\title{
LEVEL OF INFLUENCE OF SELECTED FACTORS UPON MISSOURI AGRICULTURAL EDUCATION TEACHERS' CHOICE TO INSTRUCT AGRICULTURAL MECHANICS CURRICULUM
}

\author{
Philip Ryan Saucier
}

\author{
Dr. Robert Terry, Jr., Dissertation Supervisor
}

\begin{abstract}
The purpose of this non-experimental, quantitative study was to determine: the personal, professional, and program characteristics of school-based agricultural educators in Missouri who instruct the course entitled Agricultural Construction 1 and/or Agricultural Construction 2, the curriculum areas (Arc Welding, Project Construction, Oxy/Gas and Other Cutting/Welding Processes, Woodworking, Metals, and Finishing) that these teachers instruct, the factors that influence school-based agricultural educators in Missouri to instruct the curriculum areas, and the teacher characteristics (sex, age, average number of hours spent in a week supervising student agricultural mechanics SAE projects, years of teaching experience, student enrollment in school-based agricultural education programs, university semester credit hours of agricultural mechanics coursework earned) that can explain the summated variables Importance of Teaching and Teacher Self-Efficacy based upon the six curriculum areas found within the course Agricultural Construction 1 and/or Agricultural Construction 2.
\end{abstract}

The Missouri Agricultural Mechanics Assessment was distributed via e-mail to all teachers who instructed Agricultural Construction 1 and/or Agricultural Construction 2, during the 2009-2010 academic school year $(N=257)$. A total of $203(79 \%)$ teachers 
completed the instrument. Teachers determined that Personal Importance was the most influential factor that influenced their decision to teach the agricultural mechanics curriculum areas. Administration Importance was the least influential factor that influenced Missouri agriculture teachers to instruct the agricultural mechanics curriculum areas. Overall, negligible to small results were found between teacher characteristics and the summated variables: Importance to Teach and Teacher Self-Efficacy, based upon teaching the curriculum areas. 